\title{
MICROBIOLOGICAL TESTING OF DRINKING WATER IN THE WESTERN TRANSDANUBIAN REGION OF HUNGARY USING API TESTS
}

\author{
ANIKÓ ZSENI ${ }^{1}$, ROLAND MISETA ${ }^{2} \&$ BÁLINT NÉMETH ${ }^{1}$ \\ ${ }^{1}$ Department of Environmental Engineering, Széchenyi István University, Hungary \\ ${ }^{2}$ Water Testing Laboratory, Pannon Víz Waterworks, Hungary
}

\begin{abstract}
Using standard and routine methods for drinking water microbiological quality control may lead to uncertainty. In some cases, biochemical tests for confirmation of presumptive colonies have negative results. It can also happen that the target bacteria cannot be found, but the high concentration of the background biota contaminates water sampling points or even the entire water supply system. The aim of the study was to investigate and identify bacterial colonies retrieved from water samples of drinking water supply systems using a relatively cheap, fast and easy-to-use method as well as to acquire information on the presence of pathogens in the background biota. To achieve our goals, water samples from 18 western Hungarian settlements were collected during a two month period. A total of 66 morphologically different bacterial colonies growing on four media were tested for taxonomic identification by three different API (Analytical Profile Index) tests which are suitable for the identification of bacteria at species level. Out of the 66 bacterial colonies involved in the study, 58 could be identified by API tests. During the identification, the presence of 27 different taxa were proved in the water samples. As a result of our research, species (Aeromonas hydrophila, Pseudomonas fluorescens, Burkholderia cepacia) that can cause confusion in the evaluation of water samples by forming morphologically typical colonies on the medium or presenting in high number of colony form units as background contaminants were identified. The presence of species (Pseudomonas aeruginosa, Aerococcus viridans, Aeromonas hydrophila, Gemella morbillorum, Streptococcus constellatus) which originated from the background biota on different agar plates and can cause human diseases, were also confirmed. Even if the organisms which indicate water quality degradation are not present in the water sample, the background biota may contain human pathogenic bacteria that might lead to health problems when enriched in the drinking water supply system.
\end{abstract}

Keywords: microbiology, drinking water, API test, background biota, cultivation on agar medium.

\section{INTRODUCTION}

In Hungary, the quality requirements for drinking water are laid down in Government Decree 201/2001 (X.25.) [1]. The legislation defines the chemical and microbiological parameters to be investigated and the standard methods to be used. Bacteriological water quality characteristics (total colony count, total coliforms, Escherichia coli count, Enterococci count, Pseudomonas aeruginosa count, Clostridium perfringens count) have to be identified by growing on nutrient or selective media. However, the microbiological quality control may lead to uncertainty, as in some cases biochemical tests have negative results or the target bacteria cannot be found, but the high concentration of the background biota contaminates water sampling points or even the entire water supply system.

The major objective of this study was to investigate and identify bacterial colonies retrieved from water samples of drinking water supply system using a relatively cheap, fast and easy-to-use method as well as to acquire information on the presence of pathogens in the background biota.

Several national and international research have examined the microbiological quality of water in the drinking water supply system. Lejtovicz [2] investigated the effect of 
chlorination on the microbial community of the Budapest (Hungary) water supply network. They found that the microbial community in the water supply system is characterized by a number of typical aquatic, heterotrophic bacteria, e.g. Mycobacterium, Sphingomonas, Sphingopyxis, Sphingobium, Flavobacterium and Micrococcus genus. However, as a result of chlorination, both bacterial germ count and diversity were reduced and representatives of the Mycobacterium genus prevailed as being the most resistant to chlorination.

Felföldi et al. [3] investigated the occurrence and chlorine resistance of human pathogenic Pseudomonas aeruginosa and Legionella species at several sample points in a water supply system for three months using molecular techniques. Their results demonstrated the disinfectant effect of chlorination on the water supply system. However, it was highlighted that the chlorination process in the network was only effective near to the chlorination point, because these taxa reappeared places further away from chlorination.

Kovács et al. [4] investigated the seasonal and spatial changes of microbiological water quality characteristics of water supply system in Györ (Hungary) and its surroundings by cultivation methods. They reported that in warmer periods the presence of faecal indicator bacteria Escherichia coli and Enterococcus faecalis was more frequent than in cooler periods, while in the case of Pseudomonas aeruginosa, coliform and heterotrophic bacteria the seasonal dynamics could not be detected. In addition, the water quality parameters did not depend on the different geographical locations of the water networks.

Figueira et al. [5] compared Enterobacteriaceae bacterial communities in river, wastewater and drinking water in the vicinity of Porto (Portugal) by cultivation methods. Bacteria were isolated from coliform selective media and cultures were identified using DNA-based molecular methods and API 20E test based on enzymatic reactions. The measurements detected the members of the genus Citrobacter, Enterobacter, Klebsiella and Raultella of the Enterobacteriaceae group in the largest quantity. The proportion of Klebsiella in river water samples was extremely high (above 55\%) compared to other samples. However, representatives of Raoultella were missing from the river samples. In addition, representatives of the genus Serratia, Pantoea and Hafnia were found to a lesser extent in all three water types but with similar rates (about 10\%).

\section{MATERIALS AND METHODS}

To achieve our goals, water samples from 18 western Transdanubian Hungarian settlements (Györ and its surroundings) were collected during a two month period (from the beginning of February to the end of March 2019). The investigated drinking water samples originated from the Győr, Nyúl, Kapuvár and Csorna water supply system from public outflow and user sampling points. The water is derived from porous underground water and only iron and manganese removal treatments are necessary. In some water treatment plants chlorination also occurs but regular water disinfection is not required in the investigated water supply systems.

Thirty-four water samples collected during the two month period were involved in the research and analysed by API tests to identify typical and atypical microorganisms including the ones that are not investigated and cannot be identified using the standard methods required by the relevant legislation. Out of the 34 samples, 25 water samples complied, and nine water samples did not comply with the relevant legislation using the obligatory standard methods. The presence of coliforms was detected in seven water samples using the ISO 9308-1 standard method and the presence of Pseudomonas aeruginosa was detected in three water samples using ISO 16266 standard method. (In one sample both coliforms and Pseudomonas aeruginosa were detected.) 
Water samples were processed by plate incorporation and membrane filtration methods to cultivate bacterial colonies of different appearance, which were identified at the species level using API tests. Bacterial colonies were isolated by growing on five media:

- Chromogenic coliform selective agar (Biolab, ISO 9308-1) for testing members of Family Enterobacteriaceae, using membrane filtration method (MSZ EN ISO 93081:2015).

- Pseudomonas-CN selective agar (Merck, ISO 16266) for testing nonEnterobacteriaceae Gram-negative rod-shaped bacteria, using membrane filtration method (MSZ EN ISO 16266:2008).

- Yeast extract agar (Merck, ISO 6222) for testing total colony count, using inoculation in nutrient agar culture medium (MSZ EN ISO 6222:2000).

- Salt-blood agar (ÁNTSZ, Györ, MSZ ISO 13690-2) for testing heterotroph Grampositive coccus bacteria, using membrane filtration method (MSZ ISO 136902:1989).

- Enterococcus selective agar (Biolab, ISO 7899-2) for testing Enterococci, using membrane filtration method (MSZ EN ISO 7899-2:2000).

The isolates were further cultured on non-selective Columbia agar and finally tested for taxonomic identification by three different API tests. API tests are suitable for the quick identification of clinically relevant bacteria at species level using test strips and online databases. Nowadays more than 20 API tests exist to identify species belonging to a particular bacterial group. In this study three different API tests were used:

- API 20 E kit (API 20 E 25 Strips, bioMérieux) is suitable to identify Gram-negative fermenting rod-shaped bacteria such as members of Family Enterobacteriaceae. The test can identify a total of about 100 bacterial species (e.g. Enterobacter, Escherichia, Citrobacter, Klebsiella species).

- API 20 NE kit (API 20 NE 25 Strips, bioMérieux) is suitable to identify Gramnegative non-fermenting rod-shaped bacteria. 60 species, e.g. Aeromonas and Pseudomonas species, as well as other oxidase positive bacteria can be identified.

- API 20 Strep Kit (API 20 Strep 25 Strips, bioMérieux) is suitable to identify about 50 species including Streptococci, Enterococci and closely related species.

API test strips comprise wells (microtubules) containing dehydrated substrates. The isolated bacterial suspensions were used to rehydrate each of the wells. After that the strips were incubated for the prescribed time period. In the wells different metabolic reactions of bacteria can be observed, such as enzymatic activity, fermentation of carbohydrate, catabolism of proteins or amino acids. Metabolism produces colour changes that are either spontaneous or revealed by the addition of reagents and positive and negative test results can be easily distinguished (Fig. 1).

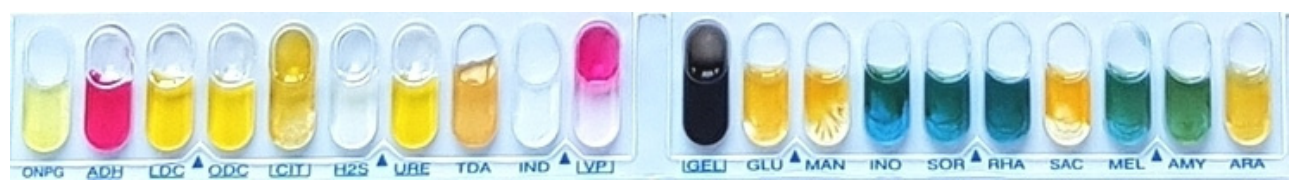

Figure 1: Colour changes of a culture in the case of API 20 E strips. 
At the end of the incubation time, a taxon-specific colour reaction sequence can be obtained. Taxonomic determination of cultures was performed using APIWEB ${ }^{\mathrm{TM}}$ software and an online database (Biomérieux [6]). The colour reaction line was recorded on the APIWEB $^{\mathrm{TM}}$ online interface, which generates a seven digit biochemical profile number (Fig. 2 ). The biochemical profile number was then compared with profile numbers in a commercial codebook (online by the APIWEB ${ }^{\mathrm{TM}}$ ) to determine the identification of the bacterial species.

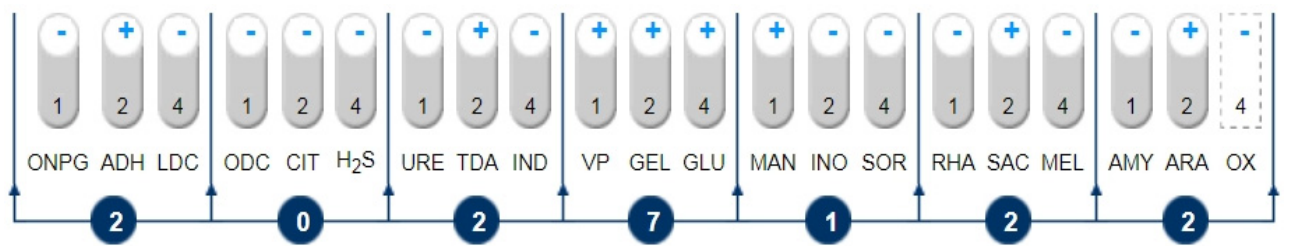

Figure 2: Biochemical profile determined by colour changes. (Source: Biomérieux [6].)

\section{RESULTS AND DISCUSSION}

During our research, 32 colonies were isolated growing on chromogenic coliform selective agar, 13 colonies on Pseudomonas-CN selective agar, seven colonies on yeast extract agar, and 14 colonies on salt-blood agar. Nevertheless, Enterococcus-positive sample did not occur during the examined period, so colonies growing on the Enterococcus selective agar could not be examined. Thus, a total of 66 morphologically different bacterial colonies growing on four media were tested for taxonomic identification by the 3 different API tests.

Fifty-eight of the 66 bacterial colonies growing on the four media could be identified by the API tests, and in eight cases the identification procedure was unsuccessful. During the identification, we could confirm the presence of 27 different taxa from the water samples by the three API tests (Table 1).

Table 1: Successfully identified bacterial colonies by the API tests (in brackets: number of samples).

\begin{tabular}{|l|l|l|}
\hline \multicolumn{1}{|c|}{ API 20 E test } & \multicolumn{1}{|c|}{ API 20 NE test } & \multicolumn{1}{c|}{ API 20 Strep test } \\
\hline Aeromonas hydrophila (6) & Pseudomonas fluorescens & Aerococcus urinae (5) \\
Serratia marcescens (2) & $(16)$ & Aerococcus viridans (3) \\
Pseudomonas sp. (2) & Achromobacter & Enterococcus avium (2) \\
Pseudomonas aeruginosa (2) & denitrificans (1) & Enterococcus faecalis (1) \\
Aeromonas salmonicida (1) & Burkholderia cepacia (1) & Gemella morbillorum (1) \\
Citrobacter freundii (1) & Chromobacterium & Lactococcus lactis (1) \\
Escherichia hermannii (1) & violaceum (1) & Streptococcus \\
Escherichia coli (1) & Ochrobactrum anthropi (1) & constellatus (1) \\
Enterobacter amnigenus (1) & Pseudomonas putida (1) & \\
Pantoea sp. (1) & Rhizobium radiobacter (1) & \\
Pseudomonas fluorescens (1) & Sphingobacterium & \\
Serratia fonticola (1) & spiritivorum (1) & \\
Serratia odorifera (1) & \multicolumn{2}{|c|}{ 23 samples, 8 taxa } \\
\hline \multicolumn{2}{|c|}{ 21 samples, 13 taxa } & \multicolumn{2}{|c}{ samples, 7 taxa } \\
\hline
\end{tabular}


Using API $20 \mathrm{E}$ test, 23 morphologically different bacterial colonies growing on chromogenic coliform selective agar was evaluated, of which 21 were successfully identified at species or genus level. Altogether 13 different taxa were detected. (One of them is Pseudomonas fluorescens, which was also identified by API 20 NE test in the case of 16 samples.)

Using API $20 \mathrm{NE}$ test, 24 colonies growing on three different media were investigated. All the 13 morphologically different bacterial colonies growing on Pseudomonas-CN selective agar were successfully identified. Three of the four rod-shaped bacterium colonies growing on yeast extract agar were successfully identified. All seven bacterial culture with atypical morphology growing on chromogenic coliform selective agar were successfully identified at species or genus level. Altogether eight different taxa were detected.

Using API 20 Strep test, 19 colonies growing on three different media were investigated. 11 of the 14 bacterial colonies growing on salt-blood agar were successfully identified. Two of the three coccus colonies growing on yeast extract agar were successfully identified. Furthermore, after microscopic cell examination, two atypical cocci growing on chromogenic coliform selective agar were investigated by API 20 Strep test, and one of them was successfully identified taxonomically. Altogether seven different taxa were detected.

The API tests confirmed the presence of coliforms in six out of the seven cases, where the presence of coliforms was detected preliminary using the ISO 9308-1 standard method. However, in one case the result of the standard method and the API test was different. The colony believed to be coliforms according to the standard method was later identified as Aeromonas hydrophila using the API 20E test. The API tests did not confirm the presence of Pseudomonas aeruginosa in the three water samples, where their presence was detected preliminary using the ISO 16266 standard method. The typical colonies were identified in two samples as Burkholderia cepacia and in one sample as Pseudomonas fluorescens by the API 20 NE test.

\subsection{Successfully identified colonies growing on chromogenic coliform selective agar}

Thirty-two colonies were isolated growing on chromogenic coliform selective agar out of which 29 were successfully identified by using the API tests: API 20 E test: 21/23 (successfully identified/isolated), API $20 \mathrm{NE}$ test: 7/7, API 20 Strep test: 1/2. The 29 isolated cultures belonged to 16 taxa.

The typical colony forming species (15 isolated culture, nine taxa) can be seen in Fig. 3(a). These involve the suspected coliform culture coloured from pink to purple according to the standard as can be seen in Fig. 4(a). A significant proportion of them (six of the 15 isolated cultures) was Aeromonas hydrophila oxidase positive bacteria, which is not included in the target group of the standard microbiological quality control. Aeromonas hydrophila is a biofilm-forming pathogen in drinking water networks (Burke et al. [7]), which may cause inflammation of the gastro-intestinal tract as well as muscle inflection, septicaemia and skin diseases (Igbinosa et al. [8]). Among the typical colonies, various Serratia species and representatives of Enterobacter, Pantoea, Citrobacter and Escherichia genus were also identified. All of them belong to coliforms (Guentzel [9]).

The elements of the background biota (14 isolated culture, seven taxa), which are atypical colony forming species are shown in Fig. 3(b) and an example in Fig. 4(b). Six of the 14 isolates were identified as Pseudomonas fluorescens, which is an environmental soil bacterium but can cause bacteremia in humans, especially in hospital environments due to the transfusion of contaminated blood product or the use of contaminated equipment 


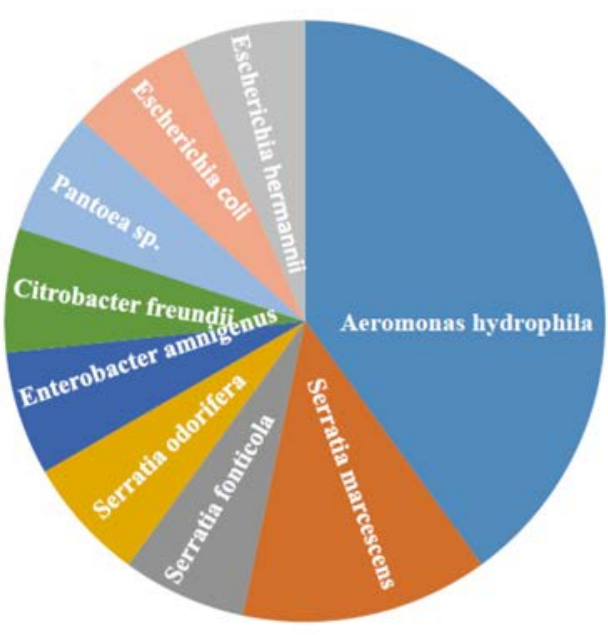

(a)

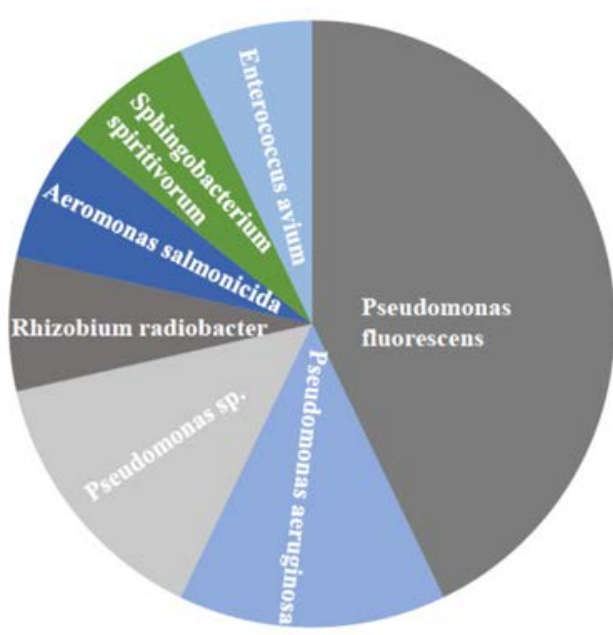

(b)

Figure 3: Successfully identified colonies growing on chromogenic coliform selective agar (29 isolated colonies, 16 taxa). (a) Typical colony forming species (15 isolated colonies, nine taxa); and (b) Atypical colony forming species (14 isolated colonies, seven taxa).

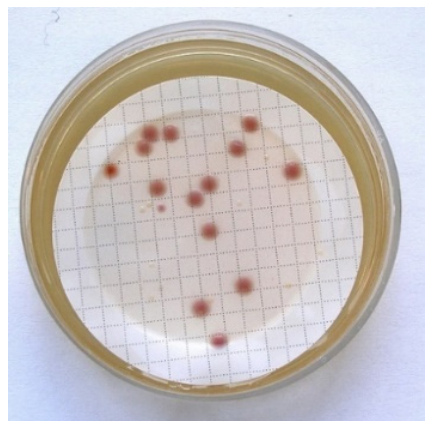

(a)

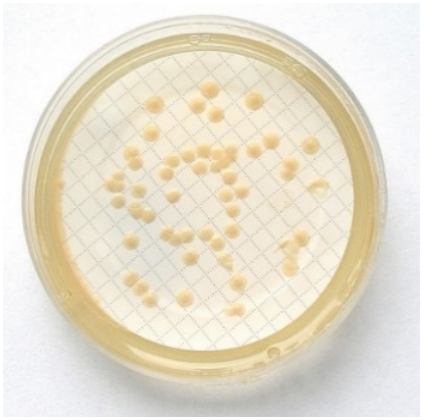

(b)

Figure 4: (a) Typical coliform-suspicious pink colonies on chromogenic coliform agar; and (b) Atypical yellow-white colonies on chromogenic coliform agar.

associated with intravenous infusions and catheters (Scales et al. [10]). Pseudomonas aeruginosa is a ubiquitous environmental bacterium. It is the most common human pathogen of the Pseudomonas, and one of the leading causes of nosocomial infections (Moradali et al. [11]). Rhizobium radiobacter nitrogen fixing soil bacteria was also identified in the background biota. Aeromonas salmonicida was first isolated in cold-water environments and is considered as pathogen of aquatic vertebrates, but Tewari et al. [12] presented the first report of Aeromonas salmonicida isolated from human blood. Sphingobacterium, which is a ubiquitous environmental bacterium genus, was also identified. It is usually isolated from soil, water and plant material, and is rarely involved in human infections (Lambiase et al. 
[13]). It is interesting that Enterococcus avium, a Gram-positive Coccus bacterium, could be identified by growing on chromogenic coliform selective agar. Enterococcus avium is a nosocomial pathogen which may cause infections of the abdominal and urinary region, but only a few reported cases are known (Patel et al. [14], Bipinchandra et al. [15]).

\subsection{Successfully identified colonies growing on Pseudomonas-CN selective agar}

Thirteen colonies were isolated growing on Pseudomonas-CN selective agar and all of them were successfully identified by using API 20 NE test. Fig. 5 shows the taxonomical distribution of colony form units isolated on Pseudomonas-CN selective agar.

The typical, bluish-green fluorescent colonies can be seen in Fig. 6, whose morphology corresponds to the standard description. The typical colony forming species (seven isolated culture, three taxa) were identified as Pseudomonas fluorescens, Pseudomonas putida (found in most soil and water habitats), and Burkholderia cepacia (Fig. 5(a)). Burkholderia cepacia is a human pathogenic bacterium (may cause pneumonia), that widely occurs in terrestrial habitats, and it has the ability to form biofilm (Coenye and Mahenthiralingam [16]).

Non-fluorescent white and greenish colonies as atypical colony forming species (six isolated culture, three taxa) were identified as Pseudomonas fluorescens, as well as two heterotrophic soil bacteria (Ochrobactrum anthropi and Achromobacter denitrificans) (Fig. $5(b))$.

\subsection{Successfully identified colonies growing on yeast extract agar}

Seven colonies were isolated growing on yeast extract agar and five of them were successfully identified by using the API tests: API 20NE test: 3/4 (successfully identified/isolated) and API 20 Strep test: 2/3. The five isolated cultures belonged to four taxa: Pseudomonas fluorescens, Chromobacterium violaceum, Gemella morbillorum and

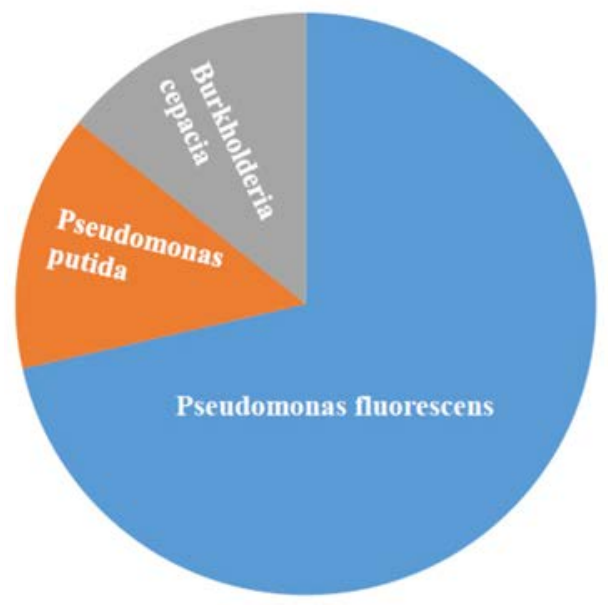

(a)

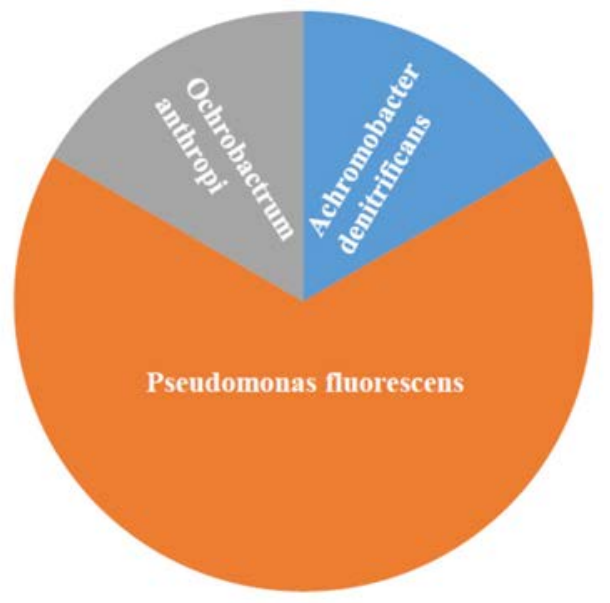

(b)

Figure 5: Successfully identified colonies growing on Pseudomonas-CN selective agar (13 isolated colonies, five taxa). (a) Typical colony forming species (seven isolated colonies, three taxa); and (b) Atypical colony forming species (six isolated colonies, three taxa). 


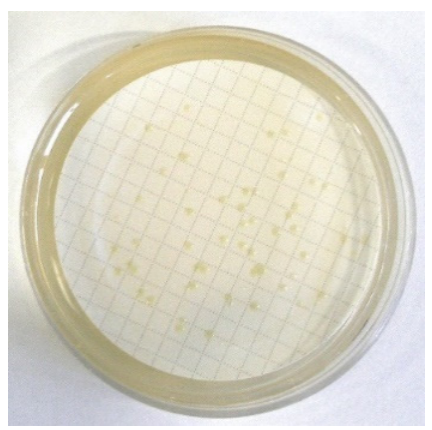

(a)

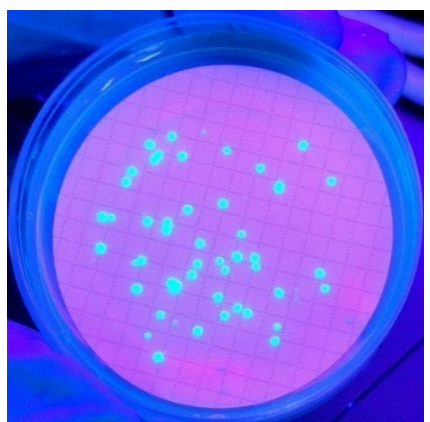

(b)

Figure 6: (a) Typical Pseudomonas-suspected colonies on Pseudomonas-selective medium under normal light; (b) Typical Pseudomonas-suspected colonies on Pseudomonas-selective medium under UV-A.

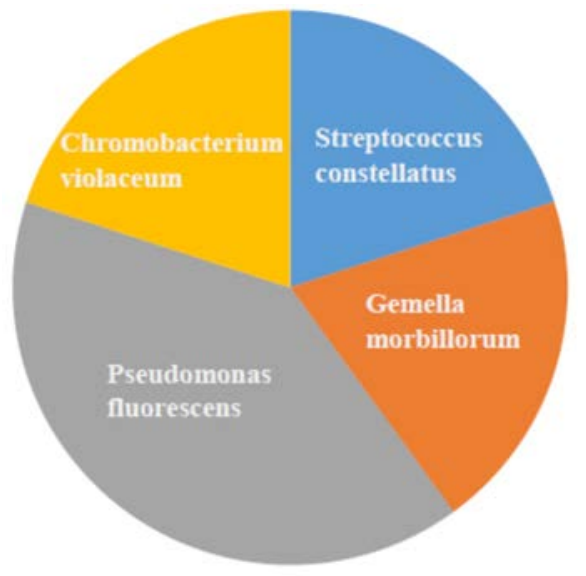

Figure 7: Successfully identified colonies growing on yeast extract agar (five isolated colonies, four taxa).

Streptococcus constellatus (Fig. 7). Chromobacterium violaceum is a facultative anaerobic environmental bacterium, common inhabitant of soil and water in tropical and subtropical regions (Ray et al. [17]). Gemella morbillorum is part of the normal microflora of the oral cavity (Vasishtha et al. [18]). Streptococcus constellatus is a member of the human intestinal and genitourinary flora (Whiley et al. [19]).

\subsection{Successfully identified colonies growing on salt-blood agar}

Fourteen colonies were isolated growing on salt-blood agar and 11 of them were successfully identified by using the API 20 Strep test: 11/14 (successfully identified/isolated). The 11 isolated cultures belonged to five taxa (Fig. 8). In the highest proportion members of the Aerococcus genus (Aerococcus urinae and Aerococcus viridans) were isolated on salt-blood agar. Aerococcus are Gram-positive cocci, which were first identified from contaminated air 
samples in the 1950s. Aerococcus urinae and Aerococcus viridians are widely distributed in hospital environments. They are considered to be predominantly nosocomial pathogens, causing urinary tract infections, bacteraemia and endocarditis, especially in weakened organisms (Parrey et al. [20], Mohan et al. [21]). However, their significance may be overlooked and easily misidentified as Streptococci or Staphylococci (Rasmussen [22]). The environmental bacterium Lactococcus lactis was also identified. It is used in dairy product fermentation as lactic acid bacteria and recognised as safe status with probiotic properties (Song et al. [23]). Although no Enterococci could be detected on the Enterococcus selective agar, we could isolate the human pathogen Enterococcus faecalis growing on salt-blood agar.

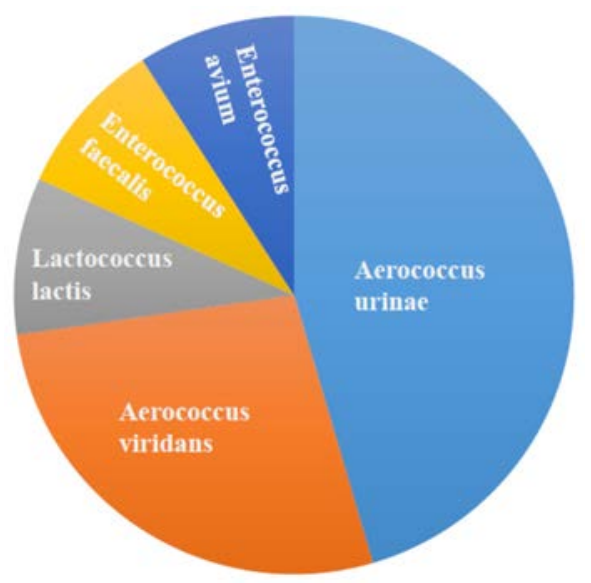

Figure 8: Successfully identified colonies growing on salt-blood agar (11 isolated colonies, five taxa).

\section{SUMMARY}

During our research, we were able to identify in drinking water samples 27 taxa at species or genus level by using API tests. Species as Aeromonas hydrophila, Pseudomonas fluorescens, Burkholderia cepacia that can cause confusion in the evaluation of water samples by forming morphologically typical colonies on the medium or presenting in high number of colony form units as background contaminants were identified. The presence of species which were originated from the background biota on different agar plates and can cause human diseases, were also confirmed: Pseudomonas aeruginosa, Aerococcus viridans, Aeromonas hydrophila, Gemella morbillorum, Streptococcus constellatus.

In the next phase of our research the connection between geographical location and microbiological composition of water samples are to be investigated using cluster analysis and principal component analysis. Although those results are not presented in this paper, the preliminary examination does not indicate connection between the water base of the sampling sites and their typical bacteriological composition, so it may be declared that the microbiological load originates from the water supply system and obviously not from the underground water base. Evaluation of samples concerning the morphology of identified taxa will also be the object of our future research.

As a conclusion, it is worth to check the drinking water supply systems using additional methods, e.g. API tests where the background biota is regularly detected in high amount by the conventional standard and routine methods. Even if the organisms which indicate water 
quality degradation are not present in the water sample, the background biota may contain human pathogenic bacteria that may lead to health problems when enriched in the drinking water supply system.

\section{ACKNOWLEDGEMENT}

The presentation of this publication was supported by the project EFOP-3.5.1-16-201700013 "Development of dual and cooperative university courses and supporting services at Széchenyi University".

\section{REFERENCES}

[1] 201/2001 (X.25.), Korm. rendelet az ivóvíz minőségi követelményeiről és az ellenőrzés rendjéröl. (201/2001 (X.25.) Government decree on drinking water quality requirements and control procedure.)

[2] Lejtovicz, Z., A budapesti ivóvízhálózat tenyészthető baktériumközösségeinek vizsgálata (Investigation of cultivable bacterial communities of the Budapest drinking water supply system). Thesis, ELTE-TTK, Budapest, 2012.

[3] Felföldi, T., Tarnóczai, T. \& Homonnay, Z.G., Presence of potential bacterial pathogens in a municipal drinking water supply system. Acta Microbiologica et Immunologica Hungarica, 57, pp. 165-179, 2010.

[4] Kovács, Z., Miseta, R. \& Zseni, A., Ivóvízminták mikrobiológiai és kémiai vizsgálata a Pannon-Víz Zrt. múködési területén (Microbiological and chemical investigation of drinking water samples on the operational area of Pannon Víz Waterworks). International Journal of Engineering and Management Sciences, 3(5), pp. 151-160, 2018. DOI: 10.21791/IJEMS.2018.5.18.

[5] Figueira, V., Serra, E.A., Vaz-Moreira, I., Brandão, T.R.S. \& Manaia, C.M., Comparison of ubiquitous antibiotic-resistant Enterobacteriaceae populations isolated from wastewaters, surface waters and drinking waters. Journal of Water and Health, 10(1), pp. 1-10, 2012. DOI: 10.2166/wh.2011.002.

[6] Biomérieux, APIWEB ${ }^{\mathrm{TM}}$ online interface. https://apiweb.biomerieux.com. Accessed on: 15 Apr. 2019.

[7] Burke, V., Robinson, J., Gracey, M., Peterson, D. \& Partridge, K., Isolation of Aeromonas hydrophila from a metropolitan water supply: Seasonal correlation with clinical isolates. Applied and Environmental Microbiology, 48(2), pp. 361-366, 1984.

[8] Igbinosa, I.H., Igumbor, E.U., Aghdasi, F., Tom, M. \& Okoh, A.I., Emerging Aeromonas species infections and their significance in public health. The Scientific World Journal, 2012, 625023, 2012. DOI: 10.1100/2012/625023.

[9] Guentzel, M.N., Escherichia, Klebsiella, Enterobacter, Serratia, Citrobacter, and Proteus. Medical Microbiology, 4th ed., ed. S. Baron, University of Texas Medical Branch at Galveston: Galveston, TX, 1996.

[10] Scales, B.S., Dickson, R.P., LiPuma, J.J. \& Huffnagle, G.B., Microbiology, genomics, and clinical significance of the Pseudomonas fluorescens species complex, an unappreciated colonizer of humans. Clinical Microbiology Reviews, 27(4), pp. 927948, 2014. DOI: 10.1128/CMR.00044-14.

[11] Moradali, M.F., Ghods, S. \& Rehm, B.H., Pseudomans aeruginosa lifestyle: A paradigm for adaptation, survival, and persistence. Frontiers in Cellular and Infection Microbiology, 7(39), pp. 1-29, 2017. DOI: 10.3389/fcimb.2017.00039.

[12] Tewari, R., Dudeja, M., Nandy, S. \& Das, A.K., Isolation of Aeromonas salmonicida from human blood sample: a case report. Journal of Clinical and Diagnostic Research, 8(2), pp. 139-140, 2014. DOI: 10.7860/JCDR/2014/6883.4032. 
[13] Lambiase, A. et al., Sphingobacterium respiratory tract infection in patients with cystic fibrosis. BMC Research Notes, 2(262), 2009.

DOI: $10.1186 / 1756-0500-2-262$.

[14] Patel, R., Keating M.R., Cockerill, F.R. \& Steckelberg, J.M., Bacteremia due to Enterococcus avium. Clinical Infectious Diseases, 17(6), pp. 1006-1011, 1993. DOI: 10.1093/clinids/17.6.1006.

[15] Bipinchandra, B., Shah, T., Roistacher, K. \& Glatt, A.E., Enterococcus avium infection. Infectious Diseases in Clinical Practice, 5(8), pp. 502-503, 1996.

[16] Coenye, T. \& Mahenthiralingam, E. (eds), Burkholderia: From Genomes to Function, Caister Academic Press: Poole, UK, 2014.

[17] Ray, P. et al., Chromobacterium violaceum septicaemia from North India. The Indian Journal of Medical Research, 120(6), pp. 523-526, 2004.

[18] Vasishtha, S., Isenberg, H.D. \& Sood, S.K., Gemella morbillorum as a cause of septic shock. Clinical Infectious Diseases, 22(6), pp. 1084-1086, 1996. DOI: 10.1093/clinids/22.6.1084.

[19] Whiley, R.A., Beighton, D., Winstanley, T.G., Fraser, H.Y. \& Hardie, J.M., Streptococcus intermedius, Streptococcus constellatus, Streptococcus anginosus (the Streptococcus milleri group): Association with different body site and clinical infections. Journal of Clinical Microbiology, 30(1), pp. 243-244, 1992.

[20] Parrey, A.H., Sofi, F., Ahmad, M. \& Kuchay, A., Aerococcus viridians infection presenting as cutaneous vasculitis in an immunocompetent patient. Reumatologia, 54(6), pp. 318-320, 2016. DOI: 10.5114/reum.2016.64909.

[21] Mohan, B., Zaman, K., Anand, N. \& Taneja, N., Aerococcus viridians: A rare pathogen causing urinary tract infection. Journal of Clinical and Diagnostic Research, 11(1), DR01-DR03, 2017. DOI: 10.7860/JCDR/2017/23997.9229.

[22] Rasmussen, M., Aerococci and aerococcal infections. Journal of Infection, 66, pp. 467-474, 2013. DOI: 10.1016/j.jinf.2012.12.006.

[23] Song, A.A., In, L., Lim, S. \& Rahim, R.A., A review on Lactococcus lactis: From food to factory. Microbial. Cell Factories, 16(1), 55(2017), 2017.

DOI: 10.1186/s12934-017-0669-x. 